\title{
Hepatitis $C$ virus infection characteristics and treatment outcomes in Canadian immigrants
}

Curtis L. Cooper ${ }^{1,2^{*}} \mathbb{D}$, Daniel Read', Marie-Louise Vachon ${ }^{3}$, Brian Conway ${ }^{4}$, Alexander Wong ${ }^{5}$, Alnoor Ramji ${ }^{6}$, Sergio Borgia ${ }^{7}$, Ed Tam $^{8}$, Lisa Barrett ${ }^{9}$, Dan Smyth ${ }^{9}$, Jordan J. Feld ${ }^{10}$, Sam Lee ${ }^{11}$ and on behalf of the CANUHC Cohort

\begin{abstract}
Background: There are multiple obstacles encountered by immigrants attempting to engage hepatitis $C$ virus $(\mathrm{HCV})$ care and treatment. We evaluated the diversity and treatment outcomes of HCV-infected immigrants evaluated for Direct Acting Antiviral (DAA) therapy in Canada.

Methods: The Canadian Network Undertaking against Hepatitis C (CANUHC) Cohort contains demographic information and DAA treatment information prospectively collected at 10 Canadian sites. Information on country of origin and race are collected. Characteristics and outcomes (sustained virological response; SVR) were compared by immigration status and race.

Results: Between January 2016 and May 2018, 725 HCV-infected patients assessed for DAA therapy were enrolled in CANUHC (mean age: $52.66 \pm 12.68$ years); $65.66 \%$ male; $82.08 \%$ White, 5.28\% Indigenous, 4.64\% South East Asian, 4.64\% East Indian, 3.36\% Black). 18.48\% were born outside of Canada. Mean age was similar [immigrants: $54.36 \pm$ 13.95 years), Canadian-born: $52.27 \pm 12.35$ years); $(p=0.085)$ ]. The overall baseline fibrosis score (in $\mathrm{kPa}$ measured by transient elastography) was similar among Canadian and foreign-born patients. Fibrosis score was not predicted by race or genotype. The proportion initiating DAA therapy was similar by immigrant status (56.72\% vs 49.92\%). SVR rates by intent-to-treat analysis were similar (immigrants-89.47\%, Canadian-born-92.52\%; $p=0.575$ ).
\end{abstract}

Conclusion: A diverse immigrant population is engaging care in Canada, initiating HCV antiviral therapy in an equitable fashion and achieving SVR proportions similar to Canada-born patients. Our Canadian experience may be of value in informing HCV elimination efforts in economically developed regions.

Keywords: Hepatitis C, Emigrants and immigrants, Antiviral drugs, Sustained Virological response

\section{Background}

Hepatitis C Virus (HCV) afflicts around 71 million individuals worldwide and is responsible for an estimated 399,000 deaths per year [1]. Direct-acting antivirals

\footnotetext{
* Correspondence: ccooper@toh.ca

'University of Ottawa, Roger Guindon Hall, 451 Smyth Rd \#2044, Ottawa, ON K1H 8M5, Canada

¿University of Ottawa, The Ottawa Hospital-General Campus, G12-501 Smyth Rd, Ottawa, ON K1H 8L6, Canada

Full list of author information is available at the end of the article
}

(DAAs) consist of a short-duration, well tolerated oral drug regime which has proven to be a breakthrough in HCV treatment leading to sustained virologic response (SVR) rates of over $90 \%$ in patients with all viral genotypes [2]. Despite the ability of DAAs to reliably cure chronic infection, HCV remains wide-spread and underdiagnosed in Canada [3, 4]. Thus, HCV remains a serious threat to health and well-being with 32,500

(c) The Author(s). 2020 Open Access This article is licensed under a Creative Commons Attribution 4.0 International License, which permits use, sharing, adaptation, distribution and reproduction in any medium or format, as long as you give appropriate credit to the original author(s) and the source, provide a link to the Creative Commons licence, and indicate if changes were made. The images or other third party material in this article are included in the article's Creative Commons licence, unless indicated otherwise in a credit line to the material. If material is not included in the article's Creative Commons licence and your intended use is not permitted by statutory regulation or exceeds the permitted use, you will need to obtain permission directly from the copyright holder. To view a copy of this licence, visit http://creativecommons.org/licenses/by/4.0/ The Creative Commons Public Domain Dedication waiver (http://creativecommons.org/publicdomain/zero/1.0/) applies to the data made available in this article, unless otherwise stated in a credit line to the data. 
Canadians projected to die from HCV-related liver complications between 2031 and 2035 [3].

Although $21.9 \%$ of Canada's population was born elsewhere, immigrants and refugees to Canada represent $35 \%$ of $\mathrm{HCV}$-infected individuals across the nation, with newcomers from endemic regions such as Sub-Saharan Africa, Asia and Eastern Europe presenting with a 1.51.7-fold higher $\mathrm{HCV}$ seroprevalence in comparison to native-born Canadians [4-6]. In addition, immigrants face many barriers to accessing healthcare including language barriers, unfavourable socioeconomic situations and cultural reservations; all of which may limit treatment uptake and/or completion [7, 8]. Failure to diagnose and treat would undoubtedly increase the risk for developing complications of HCV including hepatocellular carcinoma (HCC), which is already three-fold more common in Canadian immigrant populations $[9,10]$.

We assessed DAA treatment uptake and outcome between immigrants and Canada-born individuals utilizing patient demographic data collected at 10 treatment centres across Canada by the Canadian Network Undertaking against Hepatitis $\mathrm{C}$ (CANUHC) Cohort.

\section{Methods}

\section{Population}

The Canadian Network Undertaking against Hepatitis C (CANUHC) Cohort contains demographic and $\mathrm{HCV}$ DAA treatment information prospectively collected since January 2016 at 10 Canadian-based, publicly funding clinic sites at which patients are referred for $\mathrm{HCV}$ evaluation and antiviral treatment.

\section{Outcome measurements}

Data is obtained by case report forms completed over the course of treatment including an intake, pre-treatment, post treatment non-SVR, post treatment SVR, and annual followup forms. SVR was defined as HCV RNA negativity 12 weeks or more following completion of DAA therapy. The intake form captures data including demographic information, medical and mental health comorbidities, risk factors for $\mathrm{HCV}$ infection, previous and current $\mathrm{HCV}$ treatment history, laboratory values (hemoglobin, platelets, INR, ALT, AST, bilirubin, albumin, sodium, creatinine, GFR), HCV genotype and viral load, fibrosis stage measured in $\mathrm{kPa}$ by transient elastography, and SVR12 status. HCV infection was defined as HCV RNA positivity more than 6 months after exposure. An immigrant was defined as any person residing in Canada who was born elsewhere. Information on immigration history, country of origin and self-reported race is collected. Remote versus recent year of immigration was defined before and after the calculated median year of arrival in Canada. Social determinants of health were based on employment history and self-reported alcohol use.

\section{Statistical analysis}

Characteristics, DAA initiation, and antiviral treatment outcomes [SVR calculated by intent-to-treat (ITT) where all DAA dosed patients were included and on-treatment analysis where unknown SVR12 outcomes were excluded] were compared by immigration status and race using Student's t test, Chi square and Fisher's exact test where appropriate. New participant recruitment was censored in May 2018 but outcome data was gathered up to December 2019. Variables, which were selected based on mechanistic and biological grounds, included age, sex, race, genotype and fibrosis stage were input into the logistic model with an automated forward variable selection algorithm to find the best parsimonious model to predict SVR in the overall and immigrant population. Timing of arrival was considered in the SVR analysis limited to the immigrant population. To prevent overfitting of the model, the association of covariates with SVR had to have a significance level $\leq 0.01$ to remain in the model. Fibrosis was evaluated as a function of age, biologic sex, race, immigrant status, genotype and diabetes status by linear regression analysis. Analysis was conducted using IBM SPSS Version 26.

\section{Ethical considerations}

Participants attending CANUHC sites and providing written informed consent are enrolled. Overall research ethics board approval for this cohort study was obtained by the Health Research Ethics Board of Alberta (HREBA)-Community Health Committee (CHC) [HREBA.CHC-16-0038_REN3] where the primary database is housed. Each individual contributing site has also obtained local research ethics board approval.

\section{Results}

Of $725 \mathrm{HCV}$-infected patients assessed for DAA treatment between January 2016 and May 2018, 18.48\% ( $n=$ 134) were born outside of the country (Table 1). Among immigrants, $17.16 \%$ were born in South East Asia and the Indian Subcontinent and $6.72 \%$ originating from Sub-Saharan Africa. There was greater racial diversity in foreign-born patients. The mean age of participants was similar between groups with a mean of $54.36 \pm 13.95$ years) in foreign-born and $52.27 \pm 12.35$ years) in nativeborn patients. The median year of arrival for immigrants was 1996 (quartiles: 1981, 2004). Baseline laboratory measurements were similar between groups (Table 2).

Some differences were seen in the proportion of concurrent co-morbidities between the two groups (Table 3). The immigrant population had a higher proportion of hepatocellular carcinoma (HCC) (2.99\%) compared to native-born $(0.68 \%, p=0.042)$. Of note, this risk was not predicted by genotype 3 infection (data not shown). The immigrant population were less likely to be HIV co- 
Table 1 Baseline Characteristics and Direct Acting Antiviral Outcomes compared between Immigrant and Canadian Born Patients

\begin{tabular}{|c|c|c|c|}
\hline & $\begin{array}{l}\text { Immigrant to Canada } \\
(\boldsymbol{n}=134) \\
\mathrm{n}(\%)\end{array}$ & $\begin{array}{l}\text { Canadian Born } \\
(\boldsymbol{n}=591) \\
\mathrm{n}(\%)\end{array}$ & $\boldsymbol{P}$ Value \\
\hline Male Sex & $70(52.24)$ & $406(68.70)$ & $<0.001$ \\
\hline Race & $n=114$ & $n=511$ & $<0.001$ \\
\hline White & $53(46.49)$ & $460(90.02)$ & \\
\hline Black & $10(8.77)$ & $11(2.15)$ & \\
\hline South East Asian & $24(21.05)$ & $5(0.98)$ & \\
\hline East Indian & $26(22.81)$ & $3(0.59)$ & \\
\hline Indigenous & $1(0.88)$ & $32(6.26)$ & \\
\hline Genotype & $n=129$ & $N=571$ & $<0.001$ \\
\hline $1 a$ & $24(18.60)$ & $311(54.47)$ & \\
\hline $1 b$ & $38(29.46)$ & $53(9.28)$ & \\
\hline 1 other subtype & $4(2.33)$ & $10(1.75)$ & \\
\hline 2 & $13(10.08)$ & $59(10.33)$ & \\
\hline 3 & $32(24.81)$ & $134(23.47)$ & \\
\hline 4 & $13(10.08)$ & $2(0.35)$ & \\
\hline 6 & $5(3.88)$ & $2(0.35)$ & \\
\hline Fibrosis Stage & $N=119$ & $N=523$ & \\
\hline Stage 1 & $49(41.18)$ & 209 (39.96) & 0.589 \\
\hline Stage 2 & $20(16.81)$ & $117(22.37)$ & \\
\hline Stage 3 & $18(15.13)$ & $71(13.58)$ & \\
\hline Stage 4 (Cirrhosis) & $32(26.89)$ & $126(24.09)$ & \\
\hline Currently Employed & $54(40.30)$ & $141(23.86)$ & 0.004 \\
\hline Incarceration History & $11(8.21)$ & $154(26.06)$ & $<0.001$ \\
\hline Received Blood Product & $19(14.18)$ & $64(10.83)$ & 0.293 \\
\hline Alcohol (Past Use) & $52(38.81)$ & $218(36.89)$ & 0.693 \\
\hline Alcohol (Current Use) & $40(29.85)$ & $177(29.95)$ & $>0.999$ \\
\hline Recreational Drug Use (Ever) & $35(26.12)$ & $410(69.37)$ & $<0.001$ \\
\hline Antiviral Treatment Naïve & $40 / 69(57.97 \%)$ & $244 / 345(70.72 \%)$ & 0.037 \\
\hline Initiated a DAA Regimen & 76/134 (56.72\%) & 295/591 (49.92\%) & 0.155 \\
\hline SVR (Intent-to-Treat) & $68 / 76(89.47 \%)$ & $270 / 295$ (91.52\%) & 0.575 \\
\hline
\end{tabular}

DAA Direct Acting Antiviral, SVR Sustained Virological Response

Table 2 Baseline Laboratory Measures compared between Immigrant and Canadian Born Patients

\begin{tabular}{|c|c|c|c|}
\hline & $\begin{array}{l}\text { Immigrant to Canada } \\
\text { Mean (SD) }\end{array}$ & $\begin{array}{l}\text { Canadian Born } \\
\text { Mean (SD) }\end{array}$ & $\boldsymbol{P}$ Value \\
\hline$\overline{\mathrm{HCV}} \mathrm{RNA}(\mathrm{IU} / \mathrm{mL})$ & $1.99 \times 10^{6}\left(2.34 \times 10^{6}\right)$ & $1.59 \times 10^{6}\left(3.00 \times 10^{6}\right)$ & 0.66 \\
\hline Hemogloblin (g/L) & $137(26)$ & $140(28)$ & 0.190 \\
\hline Platelets $\left(10^{9} / \mathrm{L}\right)$ & $189(74)$ & $210(79)$ & 0.009 \\
\hline $\mathrm{ALT}(\mathrm{IU} / \mathrm{L})$ & $63(62)$ & $79(110)$ & 0.101 \\
\hline AST (IU/L) & $53(44)$ & $64(68)$ & 0.084 \\
\hline Bilirubin (mmol/L) & $11.7(6.9)$ & $11.4(8.5)$ & 0.785 \\
\hline Albumin ( $\mathrm{g} / \mathrm{L})$ & $40(11)$ & $42(36)$ & 0.588 \\
\hline Creatinine $(\mathrm{mmol} / \mathrm{L})$ & $90(102)$ & $82(61)$ & 0.314 \\
\hline eGFR & $99(78)$ & $102(120)$ & 0.808 \\
\hline
\end{tabular}


infected $(1.49 \%)$ compared to native-born $(5.92 \%, p=$ $0.031)$ and to have psychiatric illness $(11.19 \%$ vs. $23.86 \%$, $p=0.001)$. Other concurrent co-morbidities were similar between populations including diabetes $(10.45 \%$ vs. $6.43 \%, p=$ $0.135)$, chronic renal disease ( $0.75 \%$ vs. $0.51 \%, p=0.559)$, and hemodialysis ( $0 \%$ vs. $0.34 \%, p>0.999)$ in the immigrant versus the Canadian-born population, respectively.

The prevalence of particular social determinants of health was distinct between the two populations (Table 1). Compared to Canadian-born patients, the immigrant population had a higher proportion of employment $(40.30 \%$ vs. $23.86 \%$ $p=0.004)$, lower history of previous incarceration $(8.21 \%$ vs. $26.06 \%, p=<0.001)$ and present or past recreational drug use $(26.12 \%$ vs. $69.37 \%, p=<0.001)$. Other social factors were similar between both groups including past use of alcohol $(38.81 \%$ vs. $36.89 \%, p=0.69)$ and current use of alcohol ( 29.85 vs $29.95 \%, p>0.999$ ) in the immigrant and Canadianborn populations, respectively.

We compared the genotype distributions between the immigrant and the native-born Canadian group (Table 1, Fig. 1). We also specifically assessed those with advanced fibrosis (defined as METAVIR Stage F3-F4). The genotype distributions differed between groups. However, we did not identify a difference in genotype proportions by immigrant-status between advanced fibrosis patients and patients at all stages of fibrosis. The immigrant group was more likely to be genotype $1 \mathrm{~b}$ (from at least 25 different countries) and genotype 4 infected (6 of 13 from Egypt and 5 of 13 from Sub-Saharan Africa). The Canadian-born group was more likely to be genotype 1a infected. The genotype 2 and 3 proportions were similar by group and fibrosis stage categories. The mean HCV RNA levels were similar by group.

The median baseline fibrosis score determined by converted transient elastography score was fibrosis stage 2 (Table 1). Fibrosis stage was similarly distributed between the two groups $(p=0.589)$ with $41.18,16.81$, 15.13 and $26.89 \%$ of the immigrant group having a fibrosis score of F0-1, F2, F3 and F4. A fibrosis score distribution of 39.96, 22.37, 13.58 and $24.09 \%$ for F0-1, F2, F3 and F4 was observed in the Canadian-born group.
Mean fibrosis score in $\mathrm{kPa}$ by transient elastography was similar by immigration status $(11.0 \mathrm{kPa}$ in immigrants vs $10.8 \mathrm{kPa}$ in Canadian-born). By multivariable linear regression analysis, male sex, older age and diabetes (but not race or genotype) predicted higher fibrosis score by transient elastography (data not shown).

A total of 371 patients were documented to have initiated DAA regimens during the period of evaluation (Table 1). The proportions were numerically higher but statistically similar by immigrant status $(56.72 \%$ in immigrants vs $49.92 \%$ in Canadian-born, $p=0.155$ ). This did not differ between recent and remote year of arrival to Canada (data not shown). A greater proportion of the Canadian-born population were treatment naive $(70.72 \%)$ compared to the immigrant population $(57.97 \%, p=0.037)$. The most common DAA regimens prescribed during this period of evaluation included: sofosbuvir-velpatasvir (39.62\%), ledipasvir-sofosbuvir (18.33\%), elbasvir-grazoprevir (13.75\%), ombitasvir-paritaprevir/ritonavir-dasabuvir (12.13\%), and sofosbuvir-velpatasvir-voxilaprevir (2.70\%). The prescribed regimens did not differ by immigrant status $(p=0.630)$. By intent-to-treat analysis, 89.47 and $91.52 \%$ of immigrants and Canadian-born DAA recipients, respectively, achieved SVR $(p=0.575)$. The results were similar by on-treatment analysis when one case was removed due to unknown week 12 post treatment HCV RNA result. Among the immigrant group, sex, race, recent versus remote year of immigration, and genotype did not predict SVR. However, the presence of cirrhosis did predict reduced SVR in the immigrant group (76.19\% vs $93.47 \%, p=0.043)$. By multivariable analysis of the entire cohort, lower SVR was predicted by the presence of cirrhosis but not race, genotype or sex (data not shown). Data related to lost-to-follow-up, DAA adherence, on treatment viral breakthrough, post treatment viral relapse, and re-infection were not available for analysis.

\section{Discussion}

Immigrants to economically developed countries, including Canada, have a higher seroprevalence of HCV and are more likely to suffer from serious end-stage outcomes of chronic HCV infection compared to the Canadian-born population $[9,10]$. The advent of DAAs

Table 3 Concurrent Co-Morbidities compared between Immigrant and Canadian Born Patients

\begin{tabular}{llll}
\hline & $\begin{array}{l}\text { Immigrant to Canada } \\
(\boldsymbol{n}=134) \\
\mathrm{n}(\%)\end{array}$ & $\begin{array}{l}\text { Canadian Born } \\
(\boldsymbol{n}=591) \\
\mathrm{n}(\%)\end{array}$ & $\begin{array}{c}\boldsymbol{P} \text { Value } \\
\text { Liver Transplant }\end{array}$ \\
Hepatocellular Carcinoma & $4(0)$ & $4(0.17)$ & 0.999 \\
Human Immunodeficiency Virus & $2(1.49)$ & $35(5.92)$ & 0.042 \\
Chronic Renal Disease & $1(0.75)$ & $3(0.51)$ & 0.031 \\
Diabetes & $14(10.45)$ & $38(6.43)$ & 0.559 \\
Hemodialysis & $0(0)$ & $2(0.34)$ & $>0.135$ \\
Psychiatric Illness & $15(11.19)$ & $141(23.86)$ & $>0.999$ \\
\hline
\end{tabular}


Fibrosis Score F0-F4

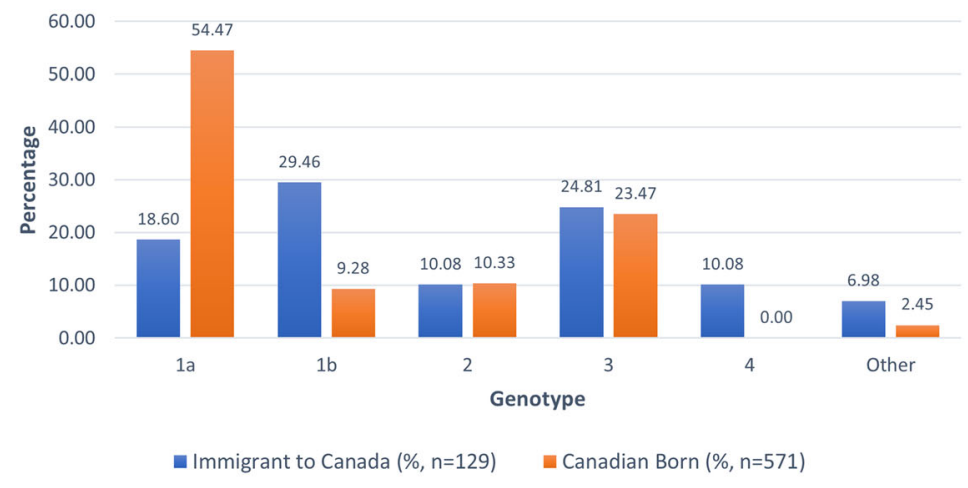

Fibrosis Score F3-F4

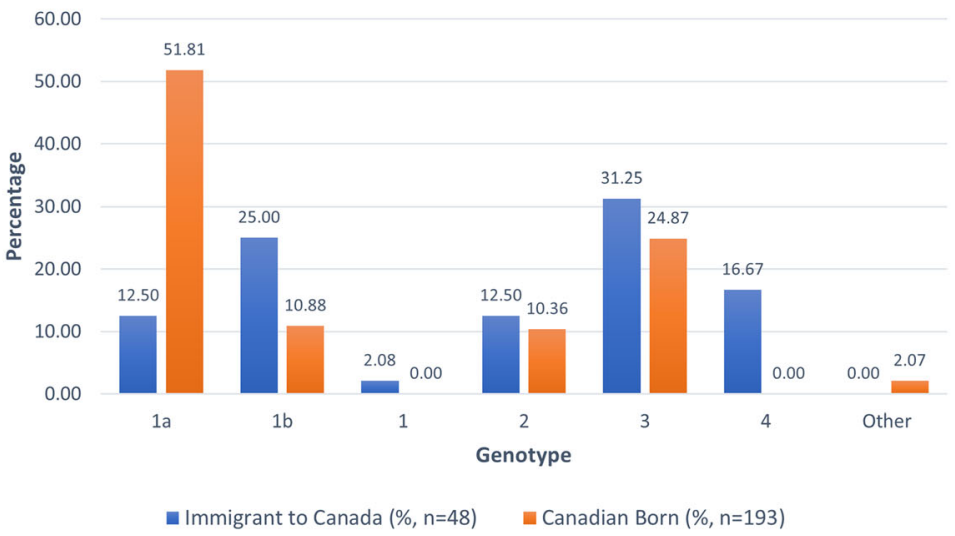

Fig. 1 HCV genotype reflects country of origin in both the immigrant and Canadian born cohort (Fibrosis Stage 0-4) and is mirrored in the distribution of those patients of each cohort with advanced fibrosis (Fibrosis Stage 3-4)

provides great promise to this population as the first easily administered, well tolerated and highly curative treatment for HCV [2]. With this in mind, it is important to assess whether the numerous barriers to healthcare often faced by immigrants impede their ability to access, adhere to and achieve cure with DAA treatments [8].

We found that the proportion of immigrants initiating DAA treatment was similar to Canadian-born patients. In these patients, SVR rates did not differ based on immigrant status and were comparable to the high cure rates seen in clinical trials. Likelihood of DAA treatment initiation and SVR were similar whether recently or remotely immigrating to Canada. Previous studies in other healthcare domains have demonstrated that immigrant populations frequently face health care engagement obstacles including differences of language, culture, custom and socioeconomic status as compared to the population of the host nation $[7,8,11]$. However, our DAA analysis is consistent with previous HCV-specific analyses identifying no distinct difference between SVR rates in Canadian-born and immigrant populations for both interferon-based and DAA treatments [12, 13]. Universal access to the publically funded Canadian health care system and full reimbursement for DAA treatment facilitated engagement and retention in $\mathrm{HCV}$ care, treatment and cure. Our analysis, further described below, suggest that $\mathrm{HCV}$ represents an unusual situation in which the non-immigrant population is characterized by a very heavy burden of psycho-socioeconomic challenges. This should be considered when interpreting the relatively good outcomes of those born outside of Canada.

We found that immigrants were less likely than Canadian-born patients to report substance abuse, previous incarceration, mental health illness and HIV coinfection. The finding of higher drug use amongst Canadian-born patients is consistent with literature suggesting that individuals from high income countries are most likely to contract $\mathrm{HCV}$ by injection drug use whereas individuals born in developing countries more commonly contract HCV through iatrogenic transmission with unsterile medical equipment $[1,10,14-16]$. Our observation of higher previous incarceration rates 
in the Canadian-borne versus immigrant population is not surprising since HCV is reported to have a seroprevalence amongst Canadian federal inmates of as high as $24.0 \%$ (versus $0.96 \%$ for Canada as a whole) [4]. Furthermore, a history of incarceration often precludes successful immigration to economically developed countries. The finding of higher HIV co-infection in the hostpopulation is consistent with previous studies and is likely in itself related to the higher rates of drug use and incarceration recorded in this study which have been identified as risk factors for HIV-HCV co-infection [10, 12, 13, 17].

The impact of unemployment on HCV treatment uptake and cure is conflicting. Some evaluations have suggested that unemployment and low socioeconomic status can present a barrier to treatment $[7,8]$. One study by Ahmed et al. suggested that new immigrants often need to take on several low-paying jobs concurrently in order to provide for their families, potentially causing interruption or discontinuation of treatment from missed appointments due to work [8]. However, Giordano et al. identified no difference in SVR with interferon-based HCV treatment between immigrants and Canadian-born patients despite a lower employment rate amongst the former [13]. In our cohort, immigrants had a higher rate of employment than the Canadian-born patient cohort. It would seem that rates of unemployment alone are not necessarily indicative of a barrier, or a lack thereof, to treatment and cure. We were limited by the fact that we did not acquire complete data about the type or quality of employment or medical benefits, which may have provided a more accurate picture of socioeconomic stability in both groups. This presents a possible avenue for future inquiry.

Like many economically developed nations, Canada is a diverse country with over one-fifth of Canadians identifying as a visible minority [5]. Discrimination in the healthcare system would have a far-reaching impact. Our finding that SVR with DAA treatment was not diminished in immigrants or in any race is reassuring given our aim for equal access to treatment in Canada. We do recognize that our analysis was limited in that it focused only on those who successfully engaged in $\mathrm{HCV}$ care and initiated treatment. With this in mind, it is plausible that both our Canadian-born and immigrant populations may have been influenced by selection bias.

We observed that $17 \%$ of our immigrant patient group originated from South East Asia and the Indian Subcontinent and 7\% originated from sub-Saharan Africa. Previous analyses have reported that migrants from South Asia and sub-Saharan Africa displayed HCV seroprevalence greater than $3 \%$ and identified those from Asia, sub-Saharan Africa and Eastern Europe as high prevalence groups for $\mathrm{HCV}$ infection [18]. The high frequency of HCV infection amongst this demographic observed in our study is further evidence in support of routine screening of immigrants $[6,10,12,19]$. Increased screening would in part address the above discussed selection bias pertaining to $\mathrm{HCV}$ treatment engagement.

There are strengths and limitations to this investigation that should be considered in addition to those mentioned above. Our cohort was derived from multiple clinics from across Canada including large $\mathrm{HCV}$ programs in Canada's five most populous and diverse urban cities. We this in mind, we believe that our results are representative of the greater population of people living with HCV in Canada. We did not have full data on year of HCV infection or diagnosis. Additional detail related to initial engagement in HCV treatment programs, adherence, language barrier, on- and post-treatment loss to follow up and viral failure/relapse would have been illuminating to help fully understand why a fairly large proportion of both immigrant and Canadian-born individuals did not initiate DAA therapy during the period of evaluation and to understand why some patients did not achieve SVR. Unfortunately, this level of detailed information was not available in this dataset.

\section{Conclusions}

We identified similarities and key differences between Canadian-born and foreign-born $\mathrm{HCV}$ patients in our cohort. The two populations were distinct in terms of race, co-morbidities and viral characteristics. Despite these discrepancies, we found that these two HCV treatment program-engaged populations experienced similar high HCV cure rates. With this in mind, we believe that these Canadian-specific findings may be of value in informing $\mathrm{HCV}$ elimination efforts in other diverse, economically developed nations.

\section{Abbreviations}

HCV: Hepatitis C; DAA: Direct Acting Antiviral; CANUHC: Canadian Network Undertaking against Hepatitis C; SVR: Sustained Virologic Response;

kPa: Kilopascal; HIV: Human Immunodeficiency Virus; HCC: Hepatocellular Carcinoma; INR: International Normalized Ratio; ALT: Alanine

Aminotransferase; AST: Aspartate Aminotransferase; GFR: Glomerular Filtration Rate; ITT: Intent-to-Treat; SD: Standard Deviation; RNA: Ribonucleic Acid

\section{Acknowledgements \\ The authors wish to thank Dr. Kris Stewart, Saskatchewan Infectious Disease Care Network, Saskatoon, Canada; Dr. Abu Hamour, Dr. AA Hamour Inc Prince George, Canada; Dr. Gisela Macphail, CUPS Liver Clinic, Calgary, Canada, Dr. Duncan Webster, Centre for Research, Education and Clinical Care of At-Risk Populations (RECAP), St-John, Canada; Dr. Chris Fraser, Cool Aid Community Health Centre, Vancouver, Canada; and Leeamma BulinckX, PerCuro Clinical Research Ltd., Victoria, Canada for case recruitments. The au- thors also thank all the clinical coordinators in the team of Canadian Network Undertaking against Hepatitis $\mathrm{C}$.}

\section{Authors' contributions}

CC: concept, data collection data collection, analysis, writing; DR: analysis, writing; MLV: writing, data collection; BC: writing, data collection; AW: writing, data collection; AR: writing, data collection; SB: data collection; ET: data collection; LB: writing, data collection; DS: writing, data collection; JF: writing, data collection; SL: writing, data collection, analysis. All authors read and approved the final manuscript. 


\section{Funding}

Funding was provided by Gilead, Merck and Abbvie pharmaceuticals. The funding bodies had no role in the design of the study and collection, analysis, and interpretation of data and in writing the manuscript.

\section{Availability of data and materials}

The datasets generated and/or analysed during the current study are not publicly available due to privacy concerns but are available from the corresponding author on reasonable request.

\section{Ethics approval and consent to participate}

The Canadian Network Undertaking against Hepatitis C (CANUHC) Cohort contains demographic and HCV DAA treatment information prospectively collected since January 2016 at 10 Canadian-based, publicly funding clinic sites at which patients are referred for HCV evaluation and antiviral treatment. Participants attending CANUHC sites and providing written informed consent are enrolled. Overall research ethics board approval for this cohort study was obtained by the Health Research Ethics Board of Alberta (HREBA)Community Health Committee (CHC) [HREBA.CHC-16-0038_REN3] where the primary database is housed. Each individual contributing site has also obtained local research ethics board approval.

\section{Consent for publication}

Not Applicable.

\section{Competing interests}

The authors have no conflicts to report.

\section{Author details}

'University of Ottawa, Roger Guindon Hall, 451 Smyth Rd \#2044, Ottawa, ON K1H 8M5, Canada. ${ }^{2}$ University of Ottawa, The Ottawa Hospital-General Campus, G12-501 Smyth Rd, Ottawa, ON K1H 8L6, Canada. ${ }^{3}$ Laval University, Ferdinand Vandry Pavillon, 1050 Avenue de la Médecine, Quebec City, Quebec GIV 0A6, Canada. ${ }^{4}$ Vancouver Infectious Diseases Centre, 1200 Burrard St, Vancouver, BC V6Z 2C7, Canada. ${ }^{5}$ University of Saskatchewan, 107 Wiggins Rd, Saskatoon, SK S7N 5E5, Canada. ${ }^{6}$ University of British Columbia, 317 - 2194 Health Sciences Mall, Vancouver, BC V6T 1Z3, Canada. ${ }^{7}$ McMaster University, Michael DeGroote Centre for Learning and Discovery (MDCL) 3104, 1280 Main Street West, Hamilton, ON L8S 4K1, Canada. ${ }^{8}$ Liver Health Centre, 750 W Broadway, Vancouver, BC V5Z 1H2, Canada. ${ }^{9}$ Dalhousie University, 5849 University Ave, Halifax, NS B3H 4R2, Canada. ${ }^{10}$ Toronto General Hospital Research Institute, 200 Elizabeth St, Toronto, ON M5G 2C4, Canada. ${ }^{11}$ Cumming School of Medicine, University of Calgary, 3330 Hospital Drive NW, Calgary, AB T2N 4N1, Canada.

Received: 25 March 2020 Accepted: 27 August 2020

Published online: 03 September 2020

\section{References}

1. World Health Organization. Global hepatitis report. Available at: http://apps. who.int/iris/bitstream/10665/255016/1/9789241565455-eng.pdf?ua=1. Accessed 19 June.

2. Falade-Nwulia O, Suarez-Cuervo C, Nelson DR, Fried MW, Segal JB, Sulkowski MS. Oral direct-acting agent therapy for hepatitis $C$ virus infection: a systematic review. Ann Intern Med. 2017;166(9):637-48.

3. Myers RP, Krajden M, Bilodeau M, et al. Burden of disease and cost of chronic hepatitis C infection in Canada. Can J Gastroenterol Hepatol. 2014; 28(5):243-50.

4. Trubnikov M, Yan P, Archibald C. Estimated prevalence of hepatitis $C$ virus infection in Canada, 2011. Can Commun Dis Rep. 2014;40(19):429-36.

5. Canada S. Immigration and ethnocultural diversity: Key results from the 2016 Census. Available at: https://www150.statcan.gc.ca/n1/en/dailyquotidien/171025/dq171025b-eng.pdf?st=pGwPtyaM. Accessed 1 June.

6. Greenaway C, Azoulay L, Allard R, et al. A population-based study of chronic hepatitis $C$ in immigrants and non-immigrants in Quebec, Canada. BMC Infect Dis. 2017;17(1):140

7. Abarca Tomas B, Pell C, Bueno Cavanillas A, Guillen Solvas J, Pool R, Roura M. Tuberculosis in migrant populations. A systematic review of the qualitative literature. PLoS One. 2013;8(12):e82440.
8. Ahmed S, Shommu NS, Rumana N, Barron GR, Wicklum S, Turin TC. Barriers to access of primary healthcare by immigrant populations in Canada: a literature review. J Immigr Minor Health. 2016;18(6):1522-40.

9. Chen W, Tomlinson G, Krahn M, Heathcote J. Immigrant patients with chronic hepatitis $\mathrm{C}$ and advanced fibrosis have a higher risk of hepatocellular carcinoma. J Viral Hepat. 2012;19(8):574-80.

10. Kamstra R, Azoulay L, Steele R, Klein MB, Greenaway C. Hospitalizations in immigrants and nonimmigrants diagnosed with chronic hepatitis $C$ infection in Quebec. Clin Infect Dis. 2016;63(11):1439-48.

11. Muggah E, Dahrouge S, Hogg W. Access to primary health care for immigrants: results of a patient survey conducted in 137 primary care practices in Ontario, Canada. BMC Fam Pract. 2012;13:128.

12. Cooper $\mathrm{CL}$, Thavorn $\mathrm{K}$, Damian $\mathrm{E}$, Corsi DJ. Hepatitis C virus infection outcomes among immigrants to Canada: a retrospective cohort analysis. Ann Hepatol. 2017:16(5):720-6.

13. Giordano C, Druyts EF, Garber G, Cooper C. Evaluation of immigration status, race and language barriers on chronic hepatitis $C$ virus infection management and treatment outcomes. Eur J Gastroenterol Hepatol. 2009; 21(9):963-8.

14. Cornberg M, Razavi HA, Alberti A, et al. A systematic review of hepatitis $C$ virus epidemiology in Europe, Canada and Israel. Liver Int. 2011;31(Suppl 2): 30-60.

15. Lavanchy D. The global burden of hepatitis C. Liver Int. 2009;29(Suppl 1):74-81.

16. Pepin J, Abou Chakra CN, Pepin E, Nault V, Valiquette L. Evolution of the global burden of viral infections from unsafe medical injections, 2000-2010. PLoS One. 2014:9(6):e99677.

17. Platt $L$, Easterbrook P, Gower E, et al. Prevalence and burden of HCV coinfection in people living with HIV: a global systematic review and metaanalysis. Lancet Infect Dis. 2016;16(7):797-808.

18. Greenaway C, Thu Ma A, Kloda LA, et al. The Seroprevalence of hepatitis C antibodies in immigrants and refugees from intermediate and high endemic countries: a systematic review and meta-analysis. PLoS One. 2015; 10(11):e0141715.

19. Greenaway C, Makarenko I, Tanveer F, Janjua NZ. Addressing hepatitis $C$ in the foreign-born population: a key to hepatitis $C$ virus elimination in Canada. Can Liver J. 2018;1(2):34-50.

\section{Publisher's Note}

Springer Nature remains neutral with regard to jurisdictional claims in published maps and institutional affiliations.

Ready to submit your research? Choose BMC and benefit from:

- fast, convenient online submission

- thorough peer review by experienced researchers in your field

- rapid publication on acceptance

- support for research data, including large and complex data types

- gold Open Access which fosters wider collaboration and increased citations

- maximum visibility for your research: over $100 \mathrm{M}$ website views per year

At $\mathrm{BMC}$, research is always in progress.

Learn more biomedcentral.com/submissions 